\title{
Penser avec de chiffres. Banque et investissements français au Mexique, 1880-1929
}

David Robichaux

Universidad Iberoamericana

david.robichaux@ibero.mx

Alejandro Tortolero Villaseñor, Penser avec de chiffres. Banque et investissements français au Mexique, 1880-1929, France, PUR, 2018, 294 pp.

Este libro, como algunos de sus anteriores, el autor nos da a conocer aspectos esenciales de la historia económica del país. Ya había destacado la importancia del reparto del agua y los bosques en la reforma agraria y la escasez del capital y hasta moneda circulante menudo durante el Porfiriato, además de contribuir a refutar algunos de los mitos propagados por la obra de Andrés Molina Enríquez en torno al mundo rural mexicano previo a la Revolución. Ahora, llevándonos al mundo de la banca y las inversiones francesas en México en el período abarcado entre 1880 y 1929, continúa nuevamente con su pasión de disputar versiones heredadas de la historia económica del Porfiriato, a través de un minucioso trabajo de archivo, o mejor dicho de archivos, en varios países. Entre ellos se destacan los archivos históricos de algunos de los más importantes bancos franceses como la Banque Nationale de Paris et des Pays-Bas, de la Société Générale, Crédit Lynonnais, además de los ministerios de relaciones exteriores de Francia y España, los Archivos Nacionales de Francia, los de la Compañía c) (i) (8) No-Comercial 4.0 Internacional.

Secuencia. E-ISSN 2395-8464 http://secuencia.mora.edu.mx/

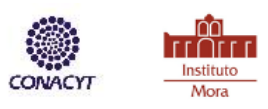


papelera San Rafael, los Archivos Rothchild de Londres y la Bibiblioteca Nettie Lee Benson de la Universidad de Tejas.

Los procesos que se propone analizar el autor son tres: 1) la contribución de la banca francesa al establecimiento del sistema bancario mexicano; 2) la interrupción de los flujos de capital con la inestabilidad producida a partir de la revolución, y 3) el desenvolvimiento de las empresas que se habían beneficiado de los flujos que continuaron creciendo y expandiéndose, sin sufrir grandes crisis por la revolución.

El argumento del libro es que la versión de un dominio abrumador del capital angloamericano debe matizarse y a través de tres capítulos el autor demuestra la importancia del capital y del imperialismo a la francesa en el proceso modernizador del Porfiriato. Comienza, en la introducción, mostrando contradicciones en las cifras que han presentado otros autores. Mientras que se ha señalado que el 94\% de las más de 500 compañías creadas entre 1890 y 1910 eran de origen anglo-americano, ¿cómo se explica el hecho de que el capital francés en México aumentó a un ritmo mucho mayor que el británico y que superaba a éste en 1911?

Pero si aquí hago mención del uso del autor de cifras para sus finos análisis de los tres procesos antes referidos, debo señalar que el título ostensiblemente se refiere al uso de las cifras, es decir, de la estadística, para una representación de México en el extranjero como país comprometido con la paz y la estabilidad, y no por el caos e inestabilidad política que lo había caracterizado antes de la Paz Porfiriana. Digo, ostensiblemente, porque, veremos en breve, que el tema del uso de la estadística en esta representación y su desarrollo en México es el objeto del primer capítulo. Pero al leer los otros dos capítulos, vemos que el autor también emplea las cifras como elemento clave de su método de análisis, ya que constantemente nos está proporcionando números para describir los procesos que se propone analizar. 
En el primer capítulo, "La construcción de las representaciones de México en Francia en el siglo XIX”, muestra cómo las cifras asumen un papel protagónico en la presentación de un México ordenado, guiado por los principios de la ciencia, en lugar entre las naciones del mundo. Esta nueva imagen, que se construye con el amplio uso de la estadística sirvió para atraer a los inversionistas y fue parte integral de la política porfirista.

Como trasfondo de las representaciones francesas de México existían ideas como las de Michel Chevalier en la primera mitad del siglo XIX de una latinidad en común y la noción de que los males producidos por la colonización española podrían ser superados si México tuviera un buen gobierno. México tenía todo en su haber para convertirse en un gran país, aliado de Francia y receptor de la misión civilizadora gala. He aquí los orígenes en el imaginario francés de la aventura imperial de Maximiliano y también de la inversión francesa en México, objeto del presente libro.

El capítulo es sumamente útil puesto que proporciona una breve historia del desarrollo de la estadística en el país desde 1821 y su creciente importancia, siguiendo el ejemplo de Francia, donde la estadística se había vuelto un valioso instrumento para gobernar. Uno de los usos de la estadística es su aplicación en las representaciones del país en distintas exposiciones internacionales, como las de Nueva Orleáns, Filadelfia y Paris, donde se fue construyendo la imagen de un país civilizado.

Por el lado francés, las descripciones de México pasaron de ser cualitativa e impresionistas a representaciones a través de las cifras. Aunque las descripciones cualitativas nunca dejaron de existir, fue la estadística - penser avec des chiffres- el elemento clave en la representación de México en Francia. El autor comienza su recorrido con la publicación culminante de esta tendencia, las Notes économiques de Raoul Bigot de 1907, puesto que este autor hace notar el paso de una perspectiva descriptiva, producto de relatos de viajes, hacia un Secuencia. E-ISSN 2395-8464 
tipo de representación basada en la estadística. Tortolero, en sus análisis, destaca el hecho de que esta perspectiva que construye un cuadro de un México de ferrocarriles, telégrafos, bancos y fábricas, y deja fuera los bajos sueldos y creciente desigualdad en el medio rural. Esta visión de un país moderno en términos tecnológicos, es la que llegó a reemplazar la de viajeros de la primera mitad del siglo XIX que se refieren a un México de bandidos, monjes, Santa Ana y la herencia española. Así, va reseñando las obras y descripciones de distintos personajes que fueron difundidas en Francia, cada uno con sus particulares énfasis y perspectivas sobre el país durante el período abarcado en el libro. Lejeune, quien señaló la necesidad de las obras de irrigación.

Jacques Kulpp, cuyas memorias Tortolero rescata de los archivos del Banque Nationale de Paris et des Pays-Bas. Descendientes de judíos de Frankfurt, Kulpp vivió en México y participó en la fundación del Banco Nacional de México en 1884. Así, el autor da a conocer y reseña diversos autores franceses que contribuyeron a crear en el imaginario de los inversionistas un México ordenado, en paz y bien gobernado. Fue particularmente interesante saber de Auguste Genin, nacido en México, y autor de varias descripciones etnográficas de mi conocimiento y su papel como promotor de esa imagen de la paz porfiriana, que él consideraba como freno al expansionismo norteamericano. En otros capítulos del libro, sobre todo el último, sabemos que Genin era miembro de consejos de administración de varias empresas con capital francés.

Terminando el primer capítulo con información sobre la fuerte presencia de los barcelonette, el autor nos prepara para el segundo capítulo que se titula "Entre representaciones y realidad: La comunidad francesa en México”. Después de proporcionar información sobre los cambios en los números de franceses, su lugar de origen y ocupaciones en distintos momentos del siglo XIX, Tortolero pasa a destacar la importancia de los negocios de los franceses en las ciudades de México, Puebla y Guadalajara. Dominan los Secuencia. E-ISSN 2395-8464 
barcelonnettes, sobre todo en tiendas de ropa y moda y en la fundación de las tiendas departamentales. De hecho, en 1914, las personas de esta aldea en los Alpes constituían el 45 por ciento de la colonia francesa.

El capítulo también proporciona un panorama de la creciente economía mexicana y el papel de la inversión extranjera en ella. Dada la importante participación de franceses o personas de ascendencia francesa- en el comercio, a veces calcular la participación del capital cada país resulta complicado. Habiendo comenzado con inversiones en la banca y la deuda, los aproximadamente cuatro mil franceses se diversificaron en sus inversiones, en tercer lugar, en cuanto a capitales, después de los norteamericanos y ligeramente después de los británicos, en 1911. Por esa época, dominaban las inversiones en deuda pública.

En el tercer, último y más largo de los capítulos, "Los inversionistas franceses y las empresas mexicanas”, el autor nos presenta casos de empresas mexicanas en las que el capital francés tuvo un papel importante. Son tratadas siete empresas: La Société foncière du Mexique, o Compañía Bancaria de Fomento y Bienes Raíces de México, S. A., la Compañía Papelera San Rafael, La Negociación Agrícola de Xico y Anexas, Azucarera del Pánuco e Ingenio San Cristóbal, la Compañía Hidroeléctrica e Irrigadora de Chapala, S. A. y la Compañía del Buen Tono.

En cada caso, el autor realiza análisis minuciosos que abarcan el período desde el origen de las personas que fundaron estas empresas durante el Porfiriato y la década de la lucha armada, además de los años posteriores, todo con el objetivo de evaluar el impacto de la Revolución sobre la rentabilidad de las empresas. En los casos de las empresas dedicadas a la agricultura, el autor presenta suficiente material como para demostrar que no todo en este sector fue atraso. Otro de los temas destacados en los casos presentados fue la importancia Secuencia. E-ISSN 2395-8464 
para el capital francés -y sin duda también para otras empresas exitosas- contar con el favor del gobierno porfirista en la forma de protecciones arancelarias y otras medidas que garantizaran condiciones casi monopólicas. Y esto es algo que se menciona en algunos de los documentos que el autor rescata de los archivos.

Considerando la importancia de la inversión francesa en el sector financiero, el autor analiza el caso de lo que fue probablemente la última empresa financiera de capital francés, la Société foncière du Mexique, o Compañía Bancaria de Fomento y Bienes Raíces de México, S. A. Creada en 1906 con un consejo de administración de personalidades con puestos destacados en otros bancos, ferrocarriles y el gobierno de la ciudad de México, la Société Foncière se dedica a tres ramas: la banca, los trabajos públicos y la inmobiliaria, teniendo como uno de sus objetivos realizar contratos de obras y servicios con el gobierno federal, así como estatales y municipales. Al crearse con capital propio, absorbe empresas existentes dedicadas a estas actividades o relacionadas con ellas, tales como la pavimentación de calles, la producción de cemento, la provisión de agua potable y alcantarillado, la construcción de aceras, la urbanización, la construcción y la inmobiliaria. Una combinación perfecta entre el poder público y el capital privado para garantizar altos niveles de utilidad y dentro del marco de la política porfirista de limitar la presencia norteamericana, favoreciendo la europea. Durante sus primeros tres años de operación ofrece a sus accionistas dividendos de diez por ciento, lo que causa la alegría a los accionistas franceses, como sabemos por las palabras de un director de escuela de una provincia francesa que expresa su entusiasmo en una carta al director de la Banque de París et de Pays-Bas que el autor rescata de los archivos.

Encontramos en este apartado reproducciones de algunos de los planos de las urbanizaciones que realizaron, como las de la Colonia Condesa, cuyo origen fue otra empresa en esta rama absorbida a la Société Foncière poco después de su incorporación. Pero además Secuencia. E-ISSN 2395-8464 
de construir vivienda y de encargarse de obras como el revestimiento de la Calzada de Tlalpan, calles aledañas al Paseo de la Reforma y la Colonia Roma y el saneamiento de las colonias San Rafael y Sta. María La Rivera, la Société Foncière también realiza inversiones en zonas rurales. Por ejemplo, adquiere haciendas en los alrededores de Guadalajara que fracciona o explota. En algunas de estas propiedades, que cuentan con importantes extensiones irrigadas y que son atravesadas por el ferrocarril se producen trigo, maíz, naranjas y alcohol. En otras propiedades rurales, en Jasso en el estado de Hidalgo, se ubica la fábrica de cemento.

Ya con la lucha armada, que afecta a algunas de estas propiedades, comienzan los problemas financieros y rescate por parte del Banco Nacional de México. Si bien es cierto que el movimiento armado tuvo cierto impacto en las zonas rurales donde la Société tenía inversiones y que la inestabilidad afectó los contratos de obras públicas urbanas, mediante un análisis detallado de los archivos, el autor nos ofrece otras razones por la quiebra de esta empresa. Ineficiencia y obsolescencia en el proceso de producción en la fábrica de cemento, negocios dudosos, mala administración, y la pérdida de la protección del gobierno y el sistema de favores. Así que, de alguna manera se puede decir que fue la revolución lo que provocó su quiebra en 1918, pero por la falta de cobijo que tenía bajo el gobierno de Díaz y que permitía que prosperara el sistema de crony capitalism o "capitalismo de amigos" parece haber tenido más peso en su quiebra.

El apartado sobre la Compañía Papelera San Rafael comienza con la presentación por parte del autor de una breve historia de la tecnología de la fabricación de papel y la inserción de dicha empresa en el paso de la producción artesanal a la industrial en México. Al conocer las características de esta empresa me acordé de mis lecturas de hace varias décadas de " $\mathrm{El}$ desarrollo del capitalismo en Rusia” de Lenin. Tal como fue ahí, en México en el Porfiriato, algunas empresas como esta papelera o la hidroeléctrica de Necaxa contaban con una Secuencia. E-ISSN 2395-8464 
tecnología más avanzada y operaban a una escala mayor que en los países de donde provenían sus máquinas. Además, la Papelera San Rafael es un caso de una eficientísima integración vertical. Fundado en 1892 por dos empresarios españoles en la región de los volcanes, se interesan inversionistas franceses y socios franceses. En 1905 se emiten acciones en la Bolsa de París y para 1910 la Banque de París y des Pay-Bas había invertido fuertemente en la empresa, estimándose que en 1910 el 80 por ciento de su capital era de origen francés.

El autor nos ofrece detalles sobre la elección del sitio que contaba con todos los elementos para la producción como aguas y bosques, además de los nexos con los empresarios de ferrocarriles que permitiría el acceso a los mercados. La riqueza de información rescatada de los archivos sobre la historia de esta empresa que nos ofrece el autor propicia el deleite de lectura -para aquellos que gozan de detalles- al saber, por ejemplo, que el lugar había estado en manos de la familia Rothschild con el objetivo de usar estos recursos para producir hierro para surtir el naciente sistema ferroviario del país.

La empresa adquiere las fábricas de sus competidores, creando una situación casi monopólica, y se especializa finalmente en el papel periódico, logrando cubrir casi la totalidad de la demanda en el país, todo esto presentado dentro de un marco construido con valiosa información sobre el tiraje de los distintos diarios y la evolución de la prensa en el período tratado. Señala el auge de la demanda al editarse un mayor número de periódicos con la caída de Porfirio Díaz y las fluctuaciones posteriores en el mercado.

El éxito de la empresa consistió en eliminar a la competencia y contar con vastos recursos forestales en distintos estados para asegurar el aprovisionamiento de materia prima, fortaleciendo así su integración vertical. En este caso, la empresa es muy afectada por la Revolución, puesto que las instalaciones fueron ocupadas por los zapatistas y hubo varias interrupciones en la producción y reducción de turnos. A pesar de algunos malos años, la Secuencia. E-ISSN 2395-8464 
empresa sobrevive la revolución y de nuevo es redituable hasta su asimilación por la papelera estatal PIPSA en 1936.

Mi resumen de lo que presenta el autor de estas dos empresas no hace justicia a la riqueza de detalles de éste y los demás casos, siempre contextualizados y a menudo ligados a intereses teóricos y contextos más amplios, propios de un avezado historiador de la economía. Siempre está en diálogo con cuestiones brevemente enunciadas que pertenecen al dominio de las discusiones sobre el desarrollo y la modernización en la historia de México.

Sólo mencionaré de manera muy breve, destacando unos puntos de los casos de las demás empresas con inversión francesa presentadas en este capítulo. Es importante destacar que el autor es particular competente para hablar de la Negociación Agrícola de Xico y Anexas, no muy lejos de la Papelera San Rafael en lo que hoy se conoce como Valle de Chalco. En otras publicaciones, ya había tratado de cómo ese despojo de los pueblos chinamperos y el drenaje del lago, en nombre de la modernidad y supuestas técnicas agrícolas superiores, tuvieron como resultado a largo plazo el desastre ecológico que hoy se presenta en repetidas inundaciones en esta zona conurbada de la ciudad de México.

Esta empresa también fue un ejemplo de la integración vertical lograda por el empresario español Iñigo Noriega al crear una empresa agrícola, el vergel de México, que surtía por ferrocarril, leche, fruta, trigo y maíz a la ciudad de México. En este apartado, al detallar el caso de una ultra-eficiente empresa agrícola, el autor continúa su polémica con el notario de Jilotepec quien había caracterizado la hacienda como un obstáculo al progreso. Una vez más, vemos cómo, a través de la pluma del autor, un estudio minucioso, con datos cuantitativos, hasta de tipo contable, sirve para desmitificar y darnos un cuadro más matizado del pasado.

Secuencia. E-ISSN 2395-8464 
No me alcanza el espacio para tratar las dos incursiones del capital francés en la industria azucarera en dos regiones de Veracruz, pero antes de terminar, quisiera resaltar unos puntos concernientes a la Compañía Hidroeléctrica e Irrigadora de Chapala y la cigarrera El Buen Tono.

La Hidroeléctrica fue creada en 1909 con la participación del Banque de París et des Pays-Bas como resultado de la fusión de varias empresas de prósperas familias tapatías que se dedicaban al servicio de tranvías en Guadalajara. Logró consolidar pequeñas productoras de electricidad que se establecieron sobre el río Santiago en una zona favorable a explotar las corrientes de agua por su declive. Por su parte, las propiedades agrícolas se beneficiaron por la baja en el nivel del Lago de Chapala y la exposición de tierras extremadamente fértiles. Así esta empresa aprovecha la expansión y crecimiento de Guadalajara proporcionándole electricidad, servicios de transporte y alimentos. Al igual que en algunos de los otros casos, la entrada del capital francés es en un momento de fusión y concentración en la acumulación de capital, la etapa de grandes economías de escala.

Solo menciono el caso del Buen Tono de paso porque gracias a ese apartado supe el origen del nombre de la calle de Pugibet donde queda el mercado de San Juan, así como la iglesia del Buen Tono y un extenso edificio de departamentos por la Calle de Bucareli cuya foto cuando era fábrica de cigarros el autor incluye en el libro. Enesto Pugibet que salió de Francia a los 15 años, y pasó cinco años en Cuba, llega México en 1875 donde pone un taller artesanal de cigarros. Desde 1888 mecaniza la producción, crea la sociedad anónima El Buen Tono en 1894 y en 1899 aumenta el capital en asociación con el Banque de Paris et des PaysBas. Mientras que en 1875 tenía cuatro empleados, ya en 1899 son 2000. Este caso es distinto de los otros presentados por el autor puesto que se trata de un francés inmigrado en México y Secuencia. E-ISSN 2395-8464 
no empresas mexicanas que reciben infusiones de capital francés. Sigue la historia de esta empresa que por un tiempo estuvo en primer lugar en el mercado en un proceso de concentración y reducción del número de empresas hasta que la eclipsó en la década de 1920 una filial de la British American Tobacco Company.

Para concluir termino refiriéndome a las propias conclusiones del autor y haciendo algunos comentarios personales. El haber revisado un gran volumen de documentos de archivo referentes al imperialismo a la francesa en México le permite al Tortolero matizar la idea de que no era importante la inversión francesa en México durante el Porfiriato. Destaca elementos como la gran presencia del capital francés en el desarrollo del sistema bancario y su actividad en los sectores financiero y comercial, sobre todo, en un momento en que el modelo de país de México estaba inspirado en Francia. Esto sucede, según el autor, en parte porque se había creado una imagen de México como un país rico dónde sólo faltaba la inversión francesa para realizar su potencial. Las inversiones galas se dirigen a sectores que no habían sido ocupados por los británicos y norteamericanos como eran los ferrocarriles y minas y tendían a colocarse en negocios donde predominaban el monopolio y la protección del Estado y, por ello, su gran rentabilidad.

Señala el autor que las empresas descritas tenían apariencia de modernidad, puesto que en papel tenían un modelo organizativo de sociedad anónima y se dividían en departamentos. Sin embargo, se trataba de una modernización superficial, de arriba hacia abajo y aunque eran sociedades anónimas, a la hora de la hora dominaban los intereses familiares.

Citando a Molina Enríquez, destaca que el secreto del éxito del régimen porfirista no fue la represión sino el repartir el pastel entre los cuates, de modo que se trataba de un gigante con pies de barro. Así su fácil derrumbe en su momento y de ahí la desprotección a los Secuencia. E-ISSN 2395-8464 
negocios, como los de inversión francesa que habían prosperado bajo su cobijo. No pudieron competir y, citando a Castañeda, dice que, con la Revolución, para México el mundo se reduce a Estados Unidos, origen de esa competencia.

Por mi parte, quisiera terminar felicitando al autor por habernos dado los frutos de un gran trabajo de archivo que no sólo arrojan luces sobre la inversión francesa en México, sino también sobre la historia del capitalismo y de distintas industrias en el país. Se trata, además, de un libro que presenta una gran cantidad de detalles organizados en torno a cuestiones esenciales para el desarrollo del país. Además, sigue ciertas líneas que ha trabajado anteriormente, ayudando a desmitificar ideas recibidas sobre cuestiones como las empresas en México, la hacienda y el porfiriato. Se trata, además, de un libro en donde abundan las cifras, pero que es accesible y ameno a leer. Se convertirá, sin duda, en una fuente de consulta obligada para la historia económica del porfiriato y habrá de cambiar nuestras percepciones sobre el período y tema, además de estimular más investigaciones al respecto. 